\title{
Synthesis of Gold Nanoparticles Using Tannin-Rich Extract and Coating onto Cotton Textiles for Catalytic Degradation of Congo Red
}

\author{
Penwisa Pisitsak (D), Kwandee Chamchoy $(\mathbb{D}$, Varanrada Chinprateep, \\ Wiphawan Khobthong, Pisutsaran Chitichotpanya $(\mathbb{D}$, and Sarute Ummartyotin
}

\author{
Department of Materials and Textile Technology, Faculty of Science and Technology, Thammasat University, \\ Pathum Thani 12120, Thailand \\ Correspondence should be addressed to Penwisa Pisitsak; penwisa_p@yahoo.com
}

Received 24 June 2021; Revised 4 August 2021; Accepted 18 August 2021; Published 10 September 2021

Academic Editor: Eduard Llobet

Copyright (c) 2021 Penwisa Pisitsak et al. This is an open access article distributed under the Creative Commons Attribution License, which permits unrestricted use, distribution, and reproduction in any medium, provided the original work is properly cited.

\begin{abstract}
Gold nanoparticles (AuNPs) were synthesized under ambient conditions from chloroauric acid in aqueous solution at $\mathrm{pH} 4$. Tannin-rich extract from Xylocarpus granatum bark was used as both reducing and capping agent, rapidly converting Au (I) salt to AuNPs. Transmission electron microscopy showed the as-prepared AuNPs to be predominantly spherical, with an average diameter of $17 \mathrm{~nm}$. The AuNPs were tested for catalytic reduction of Congo red (CR), a carcinogenic azo dye, in aqueous sodium borohydride solution. Cotton samples were coated with the AuNPs, taking on a reddish-purple color. The samples showed significantly reduced tearing strength after coating, though tensile strength was unaffected. UV-visible spectroscopy was used to determine the dye concentration in the water. CR degradation was observed only when AuNPs were present, and the efficiency of degradation was strongly linked to the AuNP loading. The AuNP-coated fabrics left only a 4.7\% CR concentration in the solution after $24 \mathrm{~h}$ and therefore promise as a heterogeneous catalyst for degradation of $\mathrm{CR}$ in aqueous solution.
\end{abstract}

\section{Introduction}

Nanostructured materials are known to be promising candidates for conversion or removal of toxic pollutants. Nanosorbents, nanoparticles, and nanocatalytic membrane systems have demonstrated effectiveness in low-energy treatment of wastewater [1]. Gold nanoparticles (AuNPs) offer a large surface-to-volume ratio, low toxicity, good biocompatibility, and unique optoelectronic properties [2]. They are increasingly used as sensory probes as well as in drug delivery, catalysis, and electronic devices [3-6]. The color of spherical AuNPs depends on their dimensions and may be brown, orange, red, or purple [7]. AuNPs have been used for the catalytic reduction of organic compounds including 4-nitrophenol [8], nitrobenzene, and Congo red [9].

Congo red (CR) is an azo dye. It is carcinogenic and toxic to many organisms. Its use in catalytic degradation has been investigated in many research studies $[10,11]$. Naseem et al. [12] present an overview of the use of nanocatalysts for reduction of $\mathrm{CR}$ in industrial wastewater. In brief, the reaction between CR and $\mathrm{NaBH}_{4}$ is thermodynamically possible but not kinetically practical, given the very low reaction rate. Interaction between borohydride ions and CR molecules requires a catalyst surface to which they can attach. The large surface area of nanocatalysts makes them suitable as an electron transfer mediator, promoting electron transfer from the borohydride ions (electron donor) to dye molecules (electron acceptor). If the correct metal nanoparticles are used, the reduction process then becomes kinetically feasible. A range of nanocatalysts have been employed in CR reduction, and rapid catalytic degradation of the dye has been demonstrated. To avoid overlapping between the surface plasmon resonance band of the nanoparticle and the absorption band of the dye, very small amounts of metal 
nanoparticles must be used. During reduction, the azo bonds of CR are cleaved to form aromatic amines [12]. Wastewater degradation of CR by AuNPs with sodium borohydride $\left(\mathrm{NaBH}_{4}\right)$ has also been demonstrated [13]. Cleavage at the azo bond releases products that have lower toxicity and are less environmentally damaging [12]. Figure 1 shows the decomposition products [13]

Nanomaterials can be derived from biological sources, including nanoparticles, wires, flowers, and tubes. Biological entities including plants and microorganisms may act as reducing or stabilizing agents in the formation of nanostructures. The use of organisms in the formation of bio(nano)materials dates back to the 1980 paper of Beveridge et al., [14] who reported that enzymes excreted by Bacillus subtilis are capable of converting metal ions, including $\mathrm{Au}$, to their elemental form, whereas physicochemical methods may require the use of toxic chemicals, whose toxicity may persist in the nanoparticles obtained; biosynthesis is more biocompatible as naturally-occurring compounds are deposited onto the nanoparticle surface [15-17]. This makes the biologically-stabilized nanoparticles more suitable in medical, cosmetic, or food applications [17].

As plant extracts are abundant and easily processed, their use in nanostructure synthesis has attracted considerable attention. Phyto-assisted synthesis is both energy-efficient and cost-effective. It requires no additional reducing agent, surfactant template, organic solvents, or use of hazardous materials [18-21]. However, biosynthesis often produces nonuniform nanoparticles at low yields. This requires finetuning of synthesis parameters such as salt concentration, ratio of biological extract to metal salt, $\mathrm{pH}$, temperature, incubation time, and aeration $[19,21]$.

Many natural products have been used in the synthesis of AuNPs from aurous ion sources including chloroauric acid $\left(\mathrm{HAuCl}_{4}\right)$ [22]. The use of plant extracts has been widely reported, including extracts from leaves, fruit, flowers, roots, seeds, and bark [23]. The morphology of the nanoparticles obtained may include spheres, quasispheres, triangles, cubics, pentagons, hexagons, rods, and plates, though spheres have been most frequently reported [20]. Particle size ranges from less than ten nanometers to a few hundred. Salmalia malabarica gum from Bombax ceiba has served as a reducing and capping agent in the synthesis of AuNPs from chloroauric acid [24]. The authors concluded that hydroxyl groups play a key role in the reduction of aurous ions. The nanoparticles were predominantly spherical with an average size of $12 \mathrm{~nm}$. Bacteria and fungi, as well as their products, have also been used in the synthesis of gold nanoparticles [25].

In this work, AuNPs were produced using bio-assisted synthesis. Extract from Xylocarpus granatum bark was chosen as the reducing agent, as it is known to have good water solubility and low toxicity [26], and is an abundant tannin-rich resource [27]. The tropical tree Xylocarpus granatum is commonly known as the cannonball mangrove. The catalytic reduction of CR in water was carried out both using the as-prepared AuNPs and AuNP-coated cotton. Cotton was selected to facilitate the handling of the nanoparticles and their removal from water after use. The mechanical properties of the coated fabrics were also evaluated.

\section{Materials and Methods}

2.1. Materials. Chloroauric acid $\left(\mathrm{HAuCl}_{4}\right)$, Congo red $\left(\mathrm{C}_{32} \mathrm{H}_{22} \mathrm{~N}_{6} \mathrm{Na}_{2} \mathrm{O}_{6} \mathrm{~S}_{2}\right)$, sodium borohydride $\left(\mathrm{NaBH}_{4}\right)$, hydrochloric acid $(\mathrm{HCl})$, and sodium hydroxide $(\mathrm{NaOH})$ were of analytical grade and were used without further purification. Whey protein isolate of $90 \%$ purity was purchased. Deionized water was used throughout. Tannin was extracted from Xylocarpus granatum by heating the sundried bark in water at $80^{\circ} \mathrm{C}$ for $1 \mathrm{~h}$ (water to bark mass ratio of $5: 1$ ) followed by spray drying to yield a reddish-brown dye powder with condensed tannin content of $74.0 \%$.

2.2. Tannin-Mediated Synthesis of AuNPs for Direct Use in the Catalytic Reduction of Congo Red (CR). A specified amount of $\mathrm{HAuCl}_{4}$ was dissolved in DI water at room temperature under vigorous stirring. Tannin powder $(0.080 \mathrm{~g})$ was then added. The total solution volume was $500 \mathrm{ml}$. The $\mathrm{pH}$ was adjusted to 4 and the mixture was stirred for a few minutes until the color became reddish-purple. $\mathrm{HAuCl}_{4}$ concentrations of $0.010 \mathrm{~g} / \mathrm{L}, 0.03 \mathrm{~g} / \mathrm{L}$, and $0.050 \mathrm{~g} / \mathrm{L}$ were used. The colloidal solutions obtained were coded AuNP-1, AuNP-3, and AuNP-5.

\subsection{Tannin-Mediated Synthesis of AuNPs and Coating of} Cotton Fabrics. Whey protein isolate (WPI) was mixed with DI water at a concentration of $0.2 \mathrm{~g} / \mathrm{L}$. Woven cotton samples of $10 \mathrm{~cm} \times 15 \mathrm{~cm}$ were coated with the WPI solution using a padding mangle at a nip pressure of $1 \mathrm{~kg} / \mathrm{cm}^{2}$ to obtain $100 \%$ wet pick-up. The coated fabrics were dried at ambient temperature and pressure. The fabrics were coated a second time with colloidal solutions containing AuNPs, prepared using $\mathrm{HAuCl}_{4}$ at concentrations of $0.1,0.6,0.8$, and $1.0 \mathrm{~g} / \mathrm{L}$. These were padded onto cotton samples, which were coded Cot-01, Cot-06, Cot-08, and Cot-10. The samples were air-dried under ambient conditions.

Excess AuNPs were removed by soaping with $2 \mathrm{~g} / \mathrm{L}$ AATCC1993 detergent at $60^{\circ} \mathrm{C}$ for $20 \mathrm{~min}$. Samples were then air-dried.

2.4. Catalytic Reduction of CR. A solution of $\mathrm{CR}, \mathrm{NaBH}_{4}$, and DI water at $\mathrm{pH} 4$ was used in evaluating the catalytic activity of AuNPs. In the first experiment, the as-prepared colloidal solution containing AuNPs was used to directly degrade $0.100 \mathrm{~g} / \mathrm{L} \mathrm{CR}$. In the second experiment, the AuNP-coated cotton samples were immersed in the $0.020 \mathrm{~g} / \mathrm{L}$ CR solution. A lower dye concentration was used in the latter experiment because the decomposition efficiency of the AuNP-coated fabrics was significantly lower than that achieved when making direct use of as-prepared nanoparticles.

2.5. Characterization. The morphology of the as-prepared AuNPs was examined using transmission electron microscopy (JEOL, JEM-2100/HR). A scanning electron microscope (JEOL, JSM-5410 LV) was used to study the morphology of the AuNP-coated fabrics. The tensile resistance of the fabrics was tested using a tensile tester (Instron 


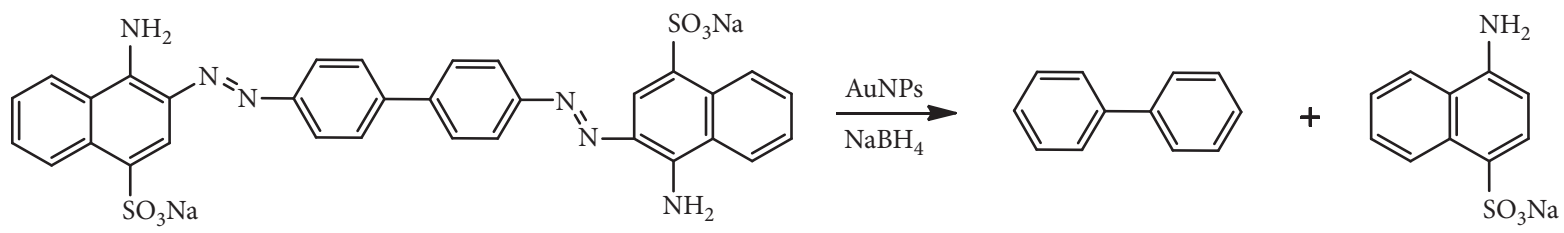

Figure 1: Catalytic reduction of CR by $\mathrm{NaBH}_{4}$ and AuNPs [13].

5567), following ASTM D5035. Tear resistance was tested using a tear tester (ElmaTear 655), following ASTM D1424. Color values were reported as CIELAB coordinates and measured using spectrophotometry (GretagMacbeth Color i5). The concentrations of the CR solutions were determined using UV-Visible spectrophotometry (PerkinElmer Lambda 25).

\section{Results and Discussion}

3.1. Synthesis of AuNPs. Successful tannin-assisted synthesis of AuNPs at $\mathrm{pH} 4$ was confirmed as the solution rapidly changed color from yellow to reddish-purple (see Figure 2). This mirrored an earlier report of AuNP synthesis using extract from banana peel at a similar range of $\mathrm{pH}$ values (2-5) [28]. This was expected as banana peel also contains phenolic compounds and tannin [29]. Under alkaline conditions $(\mathrm{pH}>7)$, the reaction mixture did not change color within $24 \mathrm{~h}$, suggesting that AuNPs had not formed.

3.2. AuNP Morphology. Transmission electron micrographs (Figure 3) showed the predominant formation of spherical gold nanoparticles with an average diameter of $17 \mathrm{~nm}$, measured using ImageJ software. The reddish-purple color was explained by the heterogeneity of the particles. Due to the range of nanoparticle sizes, the solution comprised red and blue particles, which mixed to yield an overall purple color. The smaller nanoparticles absorbed wavelengths in the blue-green spectrum and reflected red wavelengths. The larger particles absorbed red and reflected blue. The transition from red to blue in gold nanoparticles has been attributed to aggregation [30].

3.3. Morphology of AuNP-Coated Cotton. Figure 4(a) shows scanning electron micrographs of the pristine cotton and Figure 4(b) shows micrographs of Cot-10. The EDX mapping shown in Figure 4(c) confirmed that elemental gold was uniformly distributed across the fiber surface.

3.4. Color Properties of the AuNP-Coated Cotton Fabrics. As the AuNPs were reddish-purple, they imparted this color to the white cotton samples. The color values are reported in Table 1. A stronger fabric color (higher $K / S$ ) is associated with a greater AuNP loading. A higher $a^{*}$ value indicates a redder shade, while a lower $b^{*}$ value indicates a bluer shade. A lower $L^{*}$ value indicates a darker shade and was usually associated with a higher $K / S$ value. The color parameters accurately represented the appearance of the coated samples

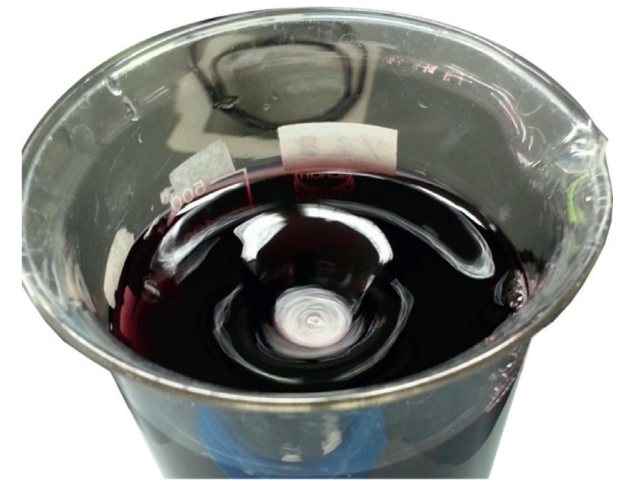

FIGURE 2: Colloidal solutions obtained by tannin-assisted synthesis of AuNPs using chloroauric acid as a precursor.

and confirmed they took on a more reddish-purple shade in the presence of an AuNP coating.

3.5. Catalytic Reduction of CR. Both the as-prepared AuNPs and the AuNP-coated cotton fabrics were effective in catalytic reduction of $\mathrm{CR}$ in water, using sodium borohydride $\left(\mathrm{NaBH}_{4}\right)$ as a reducing agent. Figure 5 shows that the CR concentration decreased with contact time, until the curves plateaued. No decomposition of CR was observed under ambient conditions, in the absence of either AuNPs or $\mathrm{NaBH}_{4}$. This confirmed that, in this system, AuNPs were required to catalyze the $\mathrm{NaBH}_{4}$ reaction. A greater AuNP loading was expected to increase dye decomposition. This was confirmed as the CR degradation time decreased from $6 \mathrm{~h}$ when using AuNP-3 to only $4 \mathrm{~h}$ when using AuNP-5. AuNP-1 and AuNP-3 were added to the CR solutions, yielding residual CR concentrations of $15.9 \%$ and $4.6 \%$ after $24 \mathrm{~h}$. The AuNP-1 curve took almost $24 \mathrm{~h}$ to plateau. As can be seen from Figure 6, the AuNP-coated fabric showed more gradual decomposition of CR than the use of AuNPs directly. In both treatments, a higher AuNP loading on the coated cotton fabrics enhanced CR degradation. CR degradation in the Cot-01 sample was comparable with that of untreated cotton. Over a $24 \mathrm{~h}$ period, the concentration of residual dye decreased by $52.4 \%$ for Cot-06 and $4.7 \%$ for Cot-10. In contrast, increasing the $\mathrm{NaBH}_{4}$ concentration from $1.00 \mathrm{~g} / \mathrm{L}$ to $2.00 \mathrm{~g} / \mathrm{L}$ had no significant effect on decomposition (data not shown). This was attributed to the $1.00 \mathrm{~g} / \mathrm{L} \mathrm{NaBH}_{4}$ concentration being sufficient to completely disintegrate the CR molecules in the system. As the cotton exhibited strong affinity to CR, absorption of CR would add to the catalytic degradation attributable to AuNPs and $\mathrm{NaBH}_{4}$. This is evident from Figure 6, which shows the CR 


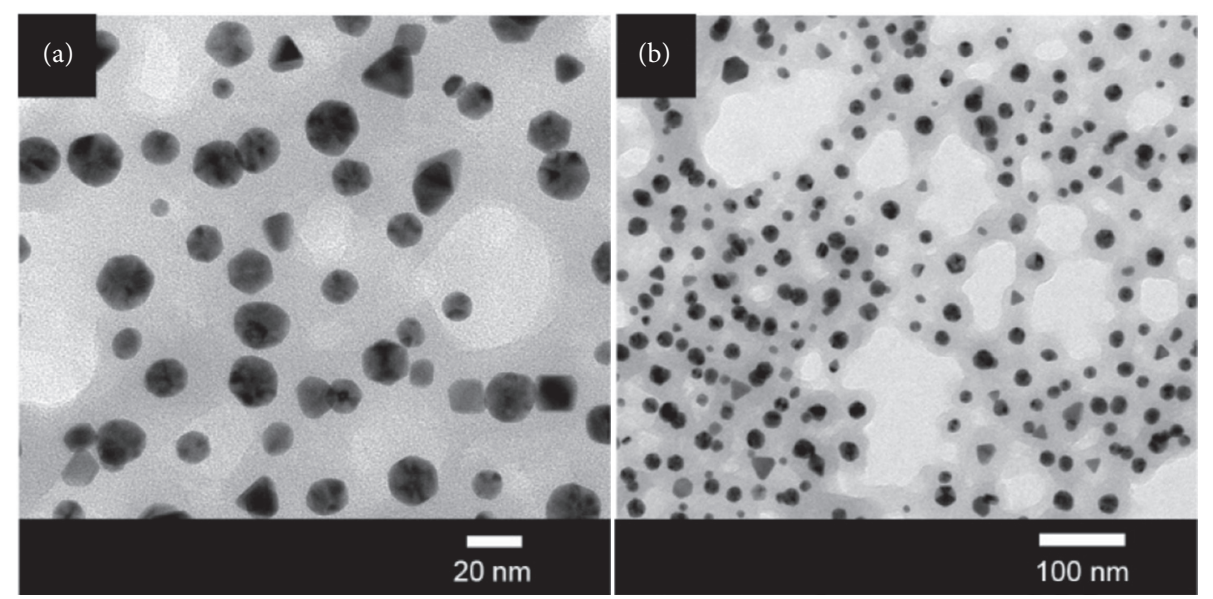

FIGURE 3: TEM images of AuNPs at different magnifications.
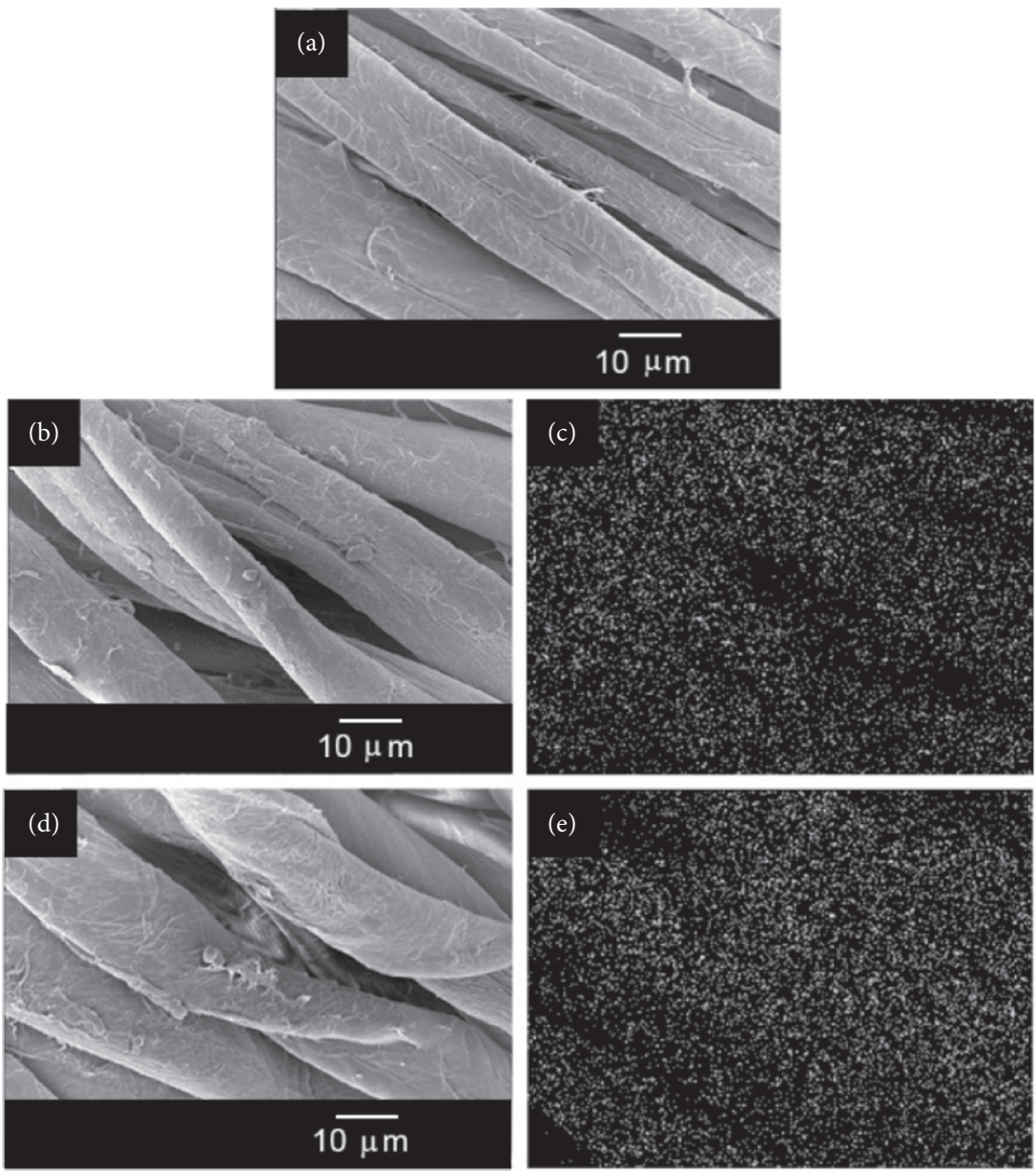

FIgURE 4: Scanning electron micrographs of cotton fabrics: (a) uncoated cotton, (b) Cot-10, and (c) EDX mapping of Cot-10.

concentration also decreases mildly with contact time in the sample that was not treated with AuNPs. Partial leaching of AuNPs from the coated fabrics was also observed.

3.6. Mechanical Properties. The WPI-coated fabrics showed significant declines in tearing strength in both warp and weft directions (Table 2). This was attributed to the WPI restricting yarn and fiber movement. This would in turn disrupt stress distribution, lower the tearing strength, and result in early breaking. WPI was necessary to prevent particle agglomeration and increase nanoparticle stability. In a previous study, we prepared silver nanoparticles (AgNPs) in a similar way, using WPI-assisted synthesis with a silver nitrate precursor. Tannin 
TABLE 1: Color values and photographic images of AuNP-coated cotton fabrics.

\begin{tabular}{|c|c|c|c|c|c|}
\hline \multirow{2}{*}{ Sample } & \multicolumn{4}{|c|}{ Color value } & \multirow{2}{*}{ Fabric image } \\
\hline & $L^{*}$ & $a^{*}$ & $b^{*}$ & $K / S$ & \\
\hline Untreated cotton & 95.88 & 7.33 & -27.23 & 0.87 & \\
\hline Cot-01 & 79.27 & 11.37 & -17.85 & 0.91 & \\
\hline Cot-10 & 53.91 & 14.70 & -11.80 & 2.21 & \\
\hline
\end{tabular}

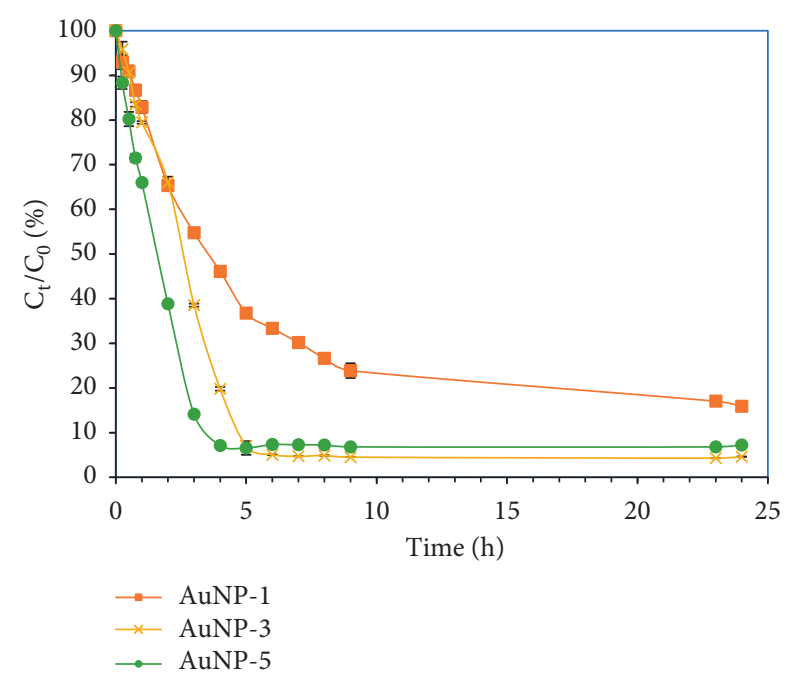

FIgure 5: Catalytic reduction of CR using AuNPs $\left(C_{0}\right.$ is the initial dye concentration, and $C$ is the dye concentration at time $t$ ).

extract was subsequently introduced to promote adhesion between the WPI-capped AgNPs and cotton samples [26]. Adding AuNPs to the WPI-coated cotton samples produced no further decrease in tearing resistance, with all coated samples showing a reduction in tearing strength of approximately $40 \%$ in both warp and weft directions.

The tensile properties of the AuNP-coated fabrics are presented in Table 3. Because the tensile and tearing forces operate in different modes, different effects result from fabric coating. All samples, coated and uncoated, had comparable tensile properties. In contrast with our previous study [31], we observed a marginal decrease in tensile strength after protein coating. However, in this work, the solution had a much lower WPI solid content $(0.20 \mathrm{~g} / \mathrm{L}$ or $0.02 \%$ solid content, compared with $1.4 \%$ in the previous work). This may have masked any negative effects of WPI on the tensile properties.

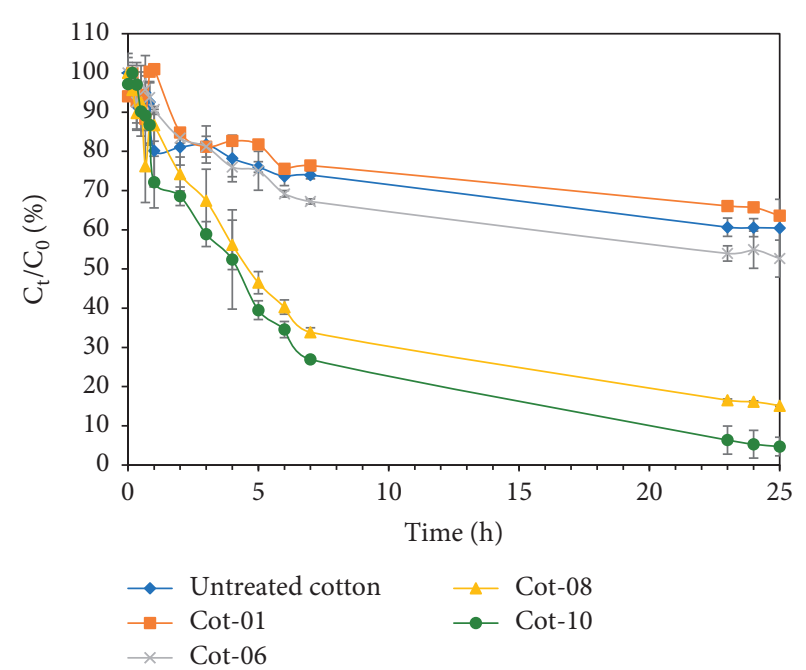

Figure 6: Catalytic reduction of CR using AuNPs-coated cotton fabrics $\left(C_{0}\right.$ is the initial dye concentration, and $C$ is the dye concentration at time $t$ ).

TABLE 2: Tearing strength values of fabric samples.

\begin{tabular}{lcc}
\hline \multirow{2}{*}{ Sample } & \multicolumn{2}{c}{ Tearing strength $(N)$} \\
& Warp & Weft \\
\hline Untreated & $11.20 \pm 0.04$ & $10.71 \pm 0.04$ \\
WPI-coated cotton & $7.10 \pm 0.04$ & $6.64 \pm 0.09$ \\
Cot-01 & $7.09 \pm 0.03$ & $6.65 \pm 0.05$ \\
Cot-10 & $6.93 \pm 0.05$ & $6.66 \pm 0.06$ \\
\hline
\end{tabular}

TABLE 3: Tensile properties of fabric samples.

\begin{tabular}{lcc}
\hline \multirow{2}{*}{ Sample } & \multicolumn{2}{c}{ Tensile strength $(N)$} \\
& Warp & Weft \\
\hline Untreated & $105.85 \pm 6.76$ & $97.36 \pm 5.27$ \\
WPI-coated cotton & $118.60 \pm 6.88$ & $109.09 \pm 15.71$ \\
Cot-01 & $123.59 \pm 10.65$ & $91.17 \pm 7.11$ \\
Cot-10 & $116.11 \pm 13.75$ & $96.01 \pm 9.53$ \\
\hline
\end{tabular}




\section{Conclusions}

We demonstrated successful synthesis of spherical gold nanoparticles from chloroauric acid and tannin in $\mathrm{pH} 4$ solution under ambient conditions. The particles had a nonuniform size distribution, with an average diameter of $17 \mathrm{~nm}$. The nanoparticles were coated onto cotton samples pretreated with whey protein isolate, via pad-drying. The coating imparted a reddish-purple color to the white fabric. Catalysis of Congo red reduction by both the as-prepared nanoparticles and the nanoparticle-coated samples was demonstrated, though the latter were significantly less efficient. The efficiency of dye decomposition was strongly linked to the nanoparticle concentration. The treatment significantly reduced tearing strength, while tensile strength was unaffected. The successful degradation of Congo red suggests that gold nanoparticle-coated cotton is a promising heterogeneous catalyst for treatment of dye-contaminated water.

\section{Data Availability}

The data used to support the finding of this study are included within the article.

\section{Disclosure}

This study was presented in part at the 59th Kasetsart University Annual Conference, Bangkok, Thailand (March, 2021).

\section{Conflicts of Interest}

The authors declare that there are no conflicts of interest regarding the publication of this paper.

\section{Acknowledgments}

This work was supported by Thammasat University Research Unit in Textile and Polymer Chemistry.

\section{References}

[1] P. K. Rai, J. Lee, S. K. Kailasa et al., "A critical review of ferrate (VI)-based remediation of soil and groundwater," Environmental Research, vol. 160, pp. 420-448, 2018.

[2] N. Elahi, M. Kamali, and M. H. Baghersad, "Recent biomedical applications of gold nanoparticles: a review," Talanta, vol. 184, pp. 537-556, 2018.

[3] R. Lévy, U. Shaheen, Y. Cesbron, and V. Sée, "Gold nanoparticles delivery in mammalian live cells: a critical review," Nano Reviews, vol. 1, no. 1, p. 4889, 2010.

[4] S. Alex and A. Tiwari, "Functionalized gold nanoparticles: synthesis, properties and applications-a review," Journal of Nanoscience and Nanotechnology, vol. 15, no. 3, pp. 18691894, 2015.

[5] J. Cao, T. Sun, and K. T. V. Grattan, "Gold nanorod-based localized surface plasmon resonance biosensors: a review," Sensors and Actuators B: Chemical, vol. 195, pp. 332-351, 2014.
[6] Y. Zhang, X. Cui, F. Shi, and Y. Deng, "Nano-gold catalysis in fine chemical synthesis," Chemical Reviews, vol. 112, no. 4, pp. 2467-2505, 2012.

[7] C. J. Orendorff, T. K. Sau, and C. J. Murphy, "Shape-dependent plasmon-resonant gold nanoparticles," Small, vol. 2, no. 5, pp. 636-639, 2006.

[8] H. R. Molina, J. L. S. Muñoz, M. I. D. Leal et al., "Carbon supported gold nanoparticles for the catalytic reduction of 4nitrophenol," Frontiers in chemistry, vol. 7, 2019.

[9] T. Kureha, Y. Nagase, and D. Suzuki, "High reusability of catalytically active gold nanoparticles immobilized in coreshell hydrogel microspheres," ACS Omega, vol. 3, no. 6, pp. 6158-6165, 2018.

[10] S. S. Royji Albeladi, M. A. Malik, and S. A. Al-thabaiti, "Facile biofabrication of silver nanoparticles using Salvia officinalis leaf extract and its catalytic activity towards Congo red dye degradation," Journal of Materials Research and Technology, vol. 9, no. 5, pp. 10031-10044, 2020.

[11] M. M. H. El-Sayed, R. E. Elsayed, A. Attia, H. H. Farghal, R. A. Azzam, and T. M. Madkour, "Novel nanoporous membranes of bio-based cellulose acetate, poly(lactic acid) and biodegradable polyurethane in-situ impregnated with catalytic cobalt nanoparticles for the removal of Methylene Blue and Congo Red dyes from wastewater," Carbohydrate Polymer Technologies and Applications, vol. 2, Article ID 100123, 2021.

[12] K. Naseem, Z. H. Farooqi, R. Begum, and A. Irfan, "Removal of Congo red dye from aqueous medium by its catalytic reduction using sodium borohydride in the presence of various inorganic nano-catalysts: a review," Journal of Cleaner Production, vol. 187, pp. 296-307, 2018.

[13] R. Subair, B. P. Tripathi, P. Formanek, F. Simon, P. Uhlmann, and M. Stamm, "Polydopamine modified membranes with in situ synthesized gold nanoparticles for catalytic and environmental applications," Chemical Engineering Journal, vol. 295, pp. 358-369, 2016.

[14] T. J. Beveridge and R. G. Murray, "Sites of metal deposition in the cell wall of Bacillus subtilis," Journal of Bacteriology, vol. 141, no. 2, pp. 876-887, 1980.

[15] P. Kuppusamy, M. M. Yusoff, G. P. Maniam, and N. Govindan, "Biosynthesis of metallic nanoparticles using plant derivatives and their new avenues in pharmacological applications-an updated report," Saudi Pharmaceutical Journal, vol. 24, no. 4, pp. 473-484, 2016.

[16] S. Ahmed, M. Ahmad, B. L. Swami, and S. Ikram, "A review on plants extract mediated synthesis of silver nanoparticles for antimicrobial applications: a green expertise," Journal of Advanced Research, vol. 7, no. 1, pp. 17-28, 2016.

[17] R. Augustine and A. Hasan, "Multimodal applications of phytonanoparticles," Phytonanotechnology, pp. 195-219, 2020.

[18] J. R. Koduru, S. K. Kailasa, J. R. Bhamore, K.-H. Kim, T. Dutta, and K. Vellingiri, "Phytochemical-assisted synthetic approaches for silver nanoparticles antimicrobial applications: a review," Advances in Colloid and Interface Science, vol. 256, pp. 326-339, 2018.

[19] P. Singh, Y.-J. Kim, D. Zhang, and D.-C. Yang, "Biological synthesis of nanoparticles from plants and microorganisms," Trends in Biotechnology, vol. 34, no. 7, pp. 588-599, 2016.

[20] J. Santhoshkumar, S. Rajeshkumar, and S. Venkat Kumar, "Phyto-assisted synthesis, characterization and applications of gold nanoparticles-a review," Biochemistry and biophysics reports, vol. 11, pp. 46-57, 2017.

[21] M. Nasrollahzadeh, M. S. Sajadi, M. Atarod, M. Sajjadi, and Z. Isaabadi, An introduction to green Nanotechnology, Academic Press, Cambridge, MA, USA, 2019. 
[22] S. Ahmed, S. Annu, S. Ikram, and S. Yudha, "Biosynthesis of gold nanoparticles: a green approach," Journal of Photochemistry and Photobiology B: Biology, vol. 161, pp. 141-153, 2016.

[23] M. Sengani, A. M. Grumezescu, and V. D. Rajeswari, "Recent trends and methodologies in gold nanoparticle synthesis-a prospective review on drug delivery aspect," OpenNano, vol. 2, pp. 37-46, 2017.

[24] B. R. Ganapuram, M. Alle, R. Dadigala, A. Dasari, V. Maragoni, and V. Guttena, "Catalytic reduction of methylene blue and Congo red dyes using green synthesized gold nanoparticles capped by salmalia malabarica gum," International Nano Letters, vol. 5, no. 4, pp. 215-222, 2015.

[25] U. Shedbalkar, R. Singh, S. Wadhwani, S. Gaidhani, and B. A. Chopade, "Microbial synthesis of gold nanoparticles: current status and future prospects," Advances in Colloid and Interface Science, vol. 209, pp. 40-48, 2014.

[26] S. Srisod, K. Motina, T. Inprasit, and P. Pisitsak, "A green and facile approach to durable antimicrobial coating of cotton with silver nanoparticles, whey protein, and natural tannin," Progress in Organic Coatings, vol. 120, pp. 123-131, 2018.

[27] P. Pisitsak, J. Hutakamol, S. Jeenapak, P. Wanmanee, J. Nuammaiphum, and R. Thongcharoen, "Natural dyeing of cotton with Xylocarpus granatum bark extract: dyeing, fastness, and ultraviolet protection properties," Fibers and Polymers, vol. 17, no. 4, pp. 560-568, 2016.

[28] A. Bankar, B. Joshi, A. Ravi Kumar, and S. Zinjarde, "Banana peel extract mediated synthesis of gold nanoparticles," Colloids and Surfaces B: Biointerfaces, vol. 80, no. 1, pp. 45-50, 2010.

[29] A. M. Aboul-Enein, Z. A. Salama, A. A. Gaafar, H. F. Aly, F. Abou-Elella, and H. Ahmed, "Identification of phenolic compounds from banana peel (Musa paradaisica L.) as antioxidant and antimicrobial agents," Journal of Chemical and Pharmaceutical Research, vol. 8, no. 4, pp. 46-55, 2016.

[30] C. Burns, W. Spendel, S. Puckett, and G. Pacey, "Solution ionic strength effect on gold nanoparticle solution color transition," Talanta, vol. 69, no. 4, pp. 873-876, 2006.

[31] P. Pisitsak, J. Hutakamol, R. Thongcharoen, P. Phokaew, K. Kanjanawan, and N. Saksaeng, "Improving the dyeability of cotton with tannin-rich natural dye through pretreatment with whey protein isolate," Industrial Crops and Products, vol. 79, pp. 47-56, 2016. 